\title{
The potential role of wild rabbits Oryctolagus cuniculus in the epidemiology of paratuberculosis in domestic ruminants
}

\author{
M. J. DANIELS ${ }^{1}$, D. HENDERSON ${ }^{2 *}$, A. GREIG ${ }^{2}$, K. STEVENSON ${ }^{3}$, J. M. SHARP ${ }^{3}$ \\ AND M. R. HUTCHINGS ${ }^{1}$ \\ ${ }^{1}$ Animal Biology Division, Scottish Agricultural College, West Mains Road, Edinburgh EH9 3JG \\ ${ }^{2}$ Veterinary Science Division, Scottish Agricultural College, Cleeve Gardens, Oakbank Road, Perth PH1 1 HF \\ ${ }^{3}$ Moredun Research Institute, International Research Centre, Pentlands Science Park, Bush Loan, Penicuick, \\ Midlothian EH26 OPZ
}

(Accepted 21 January 2003)

\section{SUMMARY}

Mycobacterium avium subspecies paratuberculosis, the organism responsible for paratuberculosis in cattle and sheep has been found in wild rabbits (Oryctolagus cuniculus) in the east of Scotland. Few studies have investigated either the level of faecal contamination by rabbits on farms, or the potential infectivity of rabbit excreta. The rate of rabbit faecal contamination deposited and the numbers encountered were estimated for 21 fields on 4 farms with a paratuberculosis problem. $7357 \pm 2571$ S.E.M. rabbit faecal pellets were deposited per hectare per day and up to 81000 pellets/ha ('standing crop') were encountered in October/November 1998. Where access to rabbits was restricted, the standing crop of faeces encountered fell to 22000 pellets/ha.

The prevalence of infection with M. a. paratuberculosis was assessed for 83 rabbits from the four farms. M. a. paratuberculosis was isolated from rabbits on all farms with an overall prevalence of $17 \%$. Out of 17 rabbits from which urine was available, M. a. paratuberculosis was isolated from two - the first reported isolation from urine in wild rabbits. The mean number of colony-forming units per gram of infected rabbit faeces was $7 \cdot 6 \times 10^{5} \pm 5 \cdot 2 \times 10^{5}$.

A relative estimate of the input of $M$. a. paratuberculosis onto pasture, at the stocking levels found on the four farms, showed that sheep and cattle potentially contributed 4 and 125 times more organisms/ha per day respectively than rabbits. However, rabbits could still contribute millions of M. a. paratuberculosis organisms per ha per day. Existing rabbit control measures on farms may be inadequate in reducing the risk of transmission to livestock.

\section{INTRODUCTION}

Mycobacterium avium subspecies paratuberculosis ( $M$. a. paratuberculosis), the organism which causes paratuberculosis (or Johne's disease) in cattle and sheep, has been found in wild rabbits (Oryctolagus cuniculus) in Scotland [1]. Evidence of a relationship between

\footnotetext{
* Author for correspondence: Animal Biology Division, Scottish Agricultural College, West Mains Road, Edinburgh EH9 3JG.
}

farms with a previous or current paratuberculosis problem in livestock and the presence of paratuberculosis in rabbits, has also been demonstrated [2]. Transmission of paratuberculosis is assumed to occur mainly through the faecal-oral route [3] and consequently there exists the potential for infected rabbit excreta to transmit the disease to grazing livestock. Few studies have investigated either the level of faecal contamination by rabbits on farms with a paratuberculosis problem, or the potential infectivity of rabbit excreta. 
Based on trapping and radio tracking, a density of between $10 \cdot 1$ and 59 rabbits/ha has been estimated for the east of Scotland [4]. Given an individual rabbit can produce between 276 and 448 faecal pellets per day $[5,6]$, then there is the potential for between 2787 and 26432 faecal pellets per ha per day to be deposited on grazing swards and latrines (accumulations of faeces used for social communication [7]).

As well as the numbers of rabbit faeces encountered on grazing swards, their relative infectivity compared to livestock faeces is also important when quantifying the potential disease risk they pose. Clinically affected cattle may shed in excess of $10^{8}$ bacilli/g of faeces [8] and sheep have been reported to excrete $1.09 \times 10^{8}$ viable bacteria/g of faeces [9].

The 'natural' infective dose required to produce clinical disease in livestock is unknown. Consequently, estimates can be based only on the doses found to produce disease in experimentally infected animals. The minimum experimental dose required to infect calves has not been determined [10] but lambs can develop infection with doses of between $10^{3}$ and $10^{9}$ organisms [11]. Consequently, calves and lambs could potentially receive an infective dose from ingesting a few grams of infected livestock faeces. Since $M$. a. paratuberculosis can survive in the environment for up to a year [12], such an infective dose could be received by ingestion of grass contaminated with faeces.

The exact role of rabbits in the epidemiology of paratuberculosis is unknown. However, regardless of their role in the transmission of paratuberculosis, rabbits are considered to have a significant economic impact on agriculture [13, 14]. On pasture, experiments have demonstrated that rabbit grazing can reduce livestock weight gain and consequently production [15]. As a result many farms practice some form of rabbit control. However, the impact of such control on the numbers of faecal pellets entering grazing pasture and consequently the potential for paratuberculosis transmission is, to date, unquantified.

Below, we describe the quantity of rabbit faeces encountered on grazing pasture on four farms in the east of Scotland where M. a. paratuberculosis had previously been isolated from both cattle and rabbits $[1,2]$. An estimate of the prevalence of infection in rabbits and their excreta is also reported. We then discuss the relative risk posed by rabbits in the transmission of paratuberculosis to livestock and the efficacy of existing rabbit control measures.

\section{METHODS}

\section{Study farms}

The four farms selected for study were at least $20 \mathrm{~km}$ apart: farms A and B in Perth and Kinross and C and D in Angus. All farms were mixed enterprises, with beef suckler herds and sheep flocks as well as arable land producing mainly feed barley and potatoes. Farms ranged in size from approximately 200-2000 ha.

All farms conducted some form of rabbit control, with three (farms A, B, C) attempting to maintain specific fields as 'rabbit free' by the use of rabbit netting. However, 'rabbit-free' fields were either not netted on all sides, had box traps which when not set allowed access to the fields or had been undermined by burrowing. Consequently rabbits were potentially able to enter these fields which are therefore classed as 'restricted access' (as opposed to rabbit free).

\section{Estimating rates of pellet deposition}

Twenty-one fields (six each from farms A, B and C and three from the smallest farm $\mathrm{D}$ which had no restricted access fields) were selected as being representative of the pasture used by grazing livestock throughout the year. Ten permanent plots $(0.5 \times 0 \cdot 5 \mathrm{~m})$ were established in two parallel lines, five at the 'edge' (defined as $<2 \mathrm{~m}$ from the field fence) and approximately $10 \mathrm{~m}$ apart and five in the 'middle' (defined as $>10 \mathrm{~m}$ from field fence) of each field. Plots were stratified between the edge and middle of fields to test whether pellets were deposited differently in relation to field position.

Each plot was marked by a wooden peg $(2 \cdot 5 \times$ $2.5 \times 16 \mathrm{~cm}$ ) at one corner. Pegs were buried until only $0.5 \mathrm{~cm}$ remained above the field surface - sufficient to enable relocation while minimizing potential effects on rabbit behaviour. Each plot was cleared of all pellets present and revisited at intervals of 14 days between November 1998 and February 1999 and the number of pellets recorded. This time period was chosen because cattle had been removed from pasture to overwinter indoors and rabbit numbers were assumed to be at their most stable then, as rabbits are least likely to breed over these months [16]. Sheep were present on all 21 fields during the study period.

\section{Estimating the 'standing crop' of rabbit faeces}

The number of faeces present on grazing pasture at any given time (i.e. the 'standing crop') is the total of accumulated faeces deposited minus losses due to 
Table 1. Mean numbers of rabbit faecal pellets deposited fortnightly per $m^{2}$ on farms in the east of Scotland (standard error means in parentheses)

\begin{tabular}{|c|c|c|c|c|c|c|c|}
\hline Farm & 8 Dec. 98 & 22 Dec. 98 & 6 Jan. 99 & 20 Jan. 99 & 3 Feb. 99 & 17 Feb. 99 & $\begin{array}{l}\text { Overall } \\
\text { mean }\end{array}$ \\
\hline A & $7 \cdot 5(0 \cdot 9)$ & $5 \cdot 3(0 \cdot 9)$ & $4 \cdot 5(0 \cdot 4)$ & $6 \cdot 7(0 \cdot 8)$ & $9 \cdot 1(1 \cdot 0)$ & $6 \cdot 7(0 \cdot 8)$ & $6 \cdot 6$ \\
\hline B & $14 \cdot 3(1 \cdot 5)$ & $18 \cdot 6(2 \cdot 6)$ & $17 \cdot 7(2 \cdot 4)$ & $18 \cdot 3(2 \cdot 1)$ & $16 \cdot 3(2 \cdot 0)$ & $15 \cdot 0(1 \cdot 8)$ & $16 \cdot 7$ \\
\hline $\mathrm{C}$ & $20 \cdot 7(3 \cdot 4)$ & $18 \cdot 5(2 \cdot 5)$ & $11 \cdot 8(1 \cdot 5)$ & $15 \cdot 7(2 \cdot 2)$ & $17 \cdot 1(1 \cdot 7)$ & $12 \cdot 1(1 \cdot 4)$ & $16 \cdot 0$ \\
\hline $\mathrm{D}$ & $1 \cdot 7(0 \cdot 3)$ & $3 \cdot 5(0 \cdot 4)$ & $2 \cdot 0(0 \cdot 3)$ & $1 \cdot 3(0 \cdot 2)$ & $1 \cdot 5(0 \cdot 2)$ & $1 \cdot 9(0 \cdot 1)$ & $2 \cdot 0$ \\
\hline Overall mean & $11 \cdot 1$ & $11 \cdot 5$ & $9 \cdot 0$ & $10 \cdot 5$ & $11 \cdot 0$ & $8 \cdot 9$ & $10 \cdot 3$ \\
\hline
\end{tabular}

Table 2. Mean numbers of rabbit pellets, latrines and sward heights encountered in fields in October/November 1998. (Backtransformed means are shown with 95\% confidence intervals, means for sward height with standard error means.)

\begin{tabular}{|c|c|c|c|c|c|}
\hline $\begin{array}{l}\text { Farm } \\
\text { (no. fields) }\end{array}$ & $\begin{array}{l}\text { Restricted } \\
\text { access? }\end{array}$ & $\begin{array}{l}\text { Field } \\
\text { position }\end{array}$ & Pellets $/ \mathrm{m}^{2}$ & Latrines $/ \mathrm{m}^{2}$ & $\begin{array}{l}\text { Sward height } \\
(\mathrm{mm})\end{array}$ \\
\hline \multicolumn{6}{|l|}{ A } \\
\hline (3) & No & $\begin{array}{l}\text { Edge } \\
\text { Middle }\end{array}$ & $\begin{array}{l}3 \cdot 8(3 \cdot 5-4 \cdot 2) \\
6 \cdot 2(5 \cdot 6-6 \cdot 8)\end{array}$ & $\begin{array}{l}0 \cdot 05(0 \cdot 05-0 \cdot 05) \\
0 \cdot 12(0 \cdot 12-0 \cdot 12)\end{array}$ & $\begin{array}{l}48 \cdot 3(3 \cdot 0) \\
48 \cdot 8(1 \cdot 5)\end{array}$ \\
\hline (3) & Yes & $\begin{array}{l}\text { Edge } \\
\text { Middle }\end{array}$ & $\begin{array}{l}0 \cdot 9(0 \cdot 7-1 \cdot 0) \\
2 \cdot 8(2 \cdot 5-3 \cdot 1)\end{array}$ & $\begin{array}{l}0.03(0.02-0.03) \\
0.02(0.02-0.02)\end{array}$ & $\begin{array}{l}63 \cdot 0(1 \cdot 9) \\
58 \cdot 8(2 \cdot 9)\end{array}$ \\
\hline \multicolumn{6}{|l|}{ B } \\
\hline (3) & No & $\begin{array}{l}\text { Edge } \\
\text { Middle }\end{array}$ & $\begin{array}{l}6 \cdot 0(5 \cdot 4-6 \cdot 6) \\
4 \cdot 0(3 \cdot 6-4 \cdot 4)\end{array}$ & $\begin{array}{l}0 \cdot 07(0 \cdot 07-0 \cdot 07) \\
0 \cdot 10(0 \cdot 10-0 \cdot 11)\end{array}$ & $\begin{array}{l}53.5(1.9) \\
59.9(1.8)\end{array}$ \\
\hline (3) & Yes & $\begin{array}{l}\text { Edge } \\
\text { Middle }\end{array}$ & $\begin{array}{l}2 \cdot 8(2 \cdot 5-3 \cdot 1) \\
7 \cdot 3(6 \cdot 7-8 \cdot 0)\end{array}$ & $\begin{array}{l}0 \cdot 12(0 \cdot 12-0 \cdot 12) \\
0 \cdot 05(0 \cdot 04-0 \cdot 05)\end{array}$ & $\begin{array}{l}81 \cdot 7(0 \cdot 3) \\
74 \cdot 7(1 \cdot 8)\end{array}$ \\
\hline \multicolumn{6}{|l|}{$\mathrm{C}$} \\
\hline (3) & No & $\begin{array}{l}\text { Edge } \\
\text { Middle }\end{array}$ & $\begin{array}{l}11 \cdot 2(10 \cdot 3-12 \cdot 2) \\
13 \cdot 1(12 \cdot 0-14 \cdot 2)\end{array}$ & $\begin{array}{l}0 \cdot 23(0 \cdot 23-0 \cdot 23) \\
0 \cdot 13(0 \cdot 13-0 \cdot 13)\end{array}$ & $\begin{array}{l}50 \cdot 0(0 \cdot 6) \\
48 \cdot 3(1 \cdot 7)\end{array}$ \\
\hline (3) & Yes & $\begin{array}{l}\text { Edge } \\
\text { Middle }\end{array}$ & $\begin{array}{l}0 \cdot 5(0 \cdot 4-0 \cdot 6) \\
0 \cdot 0(0 \cdot 0-0 \cdot 1)\end{array}$ & $\begin{array}{l}0 \cdot 00(0 \cdot 00-0 \cdot 00) \\
0 \cdot 00(0 \cdot 00-0 \cdot 00)\end{array}$ & $\begin{array}{l}81 \cdot 6(2 \cdot 4) \\
74 \cdot 8(2 \cdot 0)\end{array}$ \\
\hline \multicolumn{6}{|l|}{$\mathrm{D}$} \\
\hline (3) & No & $\begin{array}{l}\text { Edge } \\
\text { Middle }\end{array}$ & $\begin{array}{l}3 \cdot 3(3 \cdot 0-3 \cdot 6) \\
1 \cdot 3(1 \cdot 1-1 \cdot 5)\end{array}$ & $\begin{array}{l}0.07(0.07-0.08) \\
0.06(0.06-0.07)\end{array}$ & $\begin{array}{l}61 \cdot 8(2 \cdot 7) \\
60 \cdot 3(2 \cdot 0)\end{array}$ \\
\hline
\end{tabular}

decomposition, invertebrate action and uptake by grazers. In October/November 1998 estimates of the 'standing crop' of rabbit faeces was determined for each field by random stratified sampling. This time period was chosen because rabbit numbers were likely to be at their highest [16], the sward at its lowest and consequently grazing livestock, still at pasture as opposed to being overwintered indoors, are at the highest exposure risk.

Forty $0.5 \mathrm{~m} \times 0.5 \mathrm{~m}$ plots were assessed by throwing a quadrat: 20 at the edge and 20 in the middle (as defined above). Where a quadrat landed on a latrine (see below) or an area of scrub (gorse or rushes), bare rock or standing water, it was ignored and another thrown. The number of pellets deposited within each quadrat was recorded, as was the average of five random sward heights measured with a sward stick [17].

The number of latrines (defined as where pellets were encountered at densities $>20$ pellets $/ \mathrm{m}^{2}$ ) were recorded for ten $1 \times 50 \mathrm{~m}$ quadrats placed randomly: five at the edge and five in the middle of each field. Three of the six fields on each of farms A, B and C were classed as 'restricted access' and three were not. All three fields on farm D were classed as having no restricted access.

\section{Prevalence of infection in rabbits and infectivity of excreta}

Between 14 and 26 rabbits were collected from each farm between August 1998 and December 1999 to 
Table 3. Numbers of wild rabbits tested for M. a. paratuberculosis on four farms in the east of Scotland. (Numbers in parentheses are positive isolates of M. a. paratuberculosis from either lymph node, intestine or faeces samples.)

\begin{tabular}{lclcccr}
\hline \hline Farm & $\begin{array}{l}\text { Adult } \\
\text { males }\end{array}$ & $\begin{array}{l}\text { Juvenile } \\
\text { males }\end{array}$ & $\begin{array}{l}\text { Adult } \\
\text { females }\end{array}$ & $\begin{array}{l}\text { Juvenile } \\
\text { females }\end{array}$ & Total & $\%$ \\
\hline A & $9(1)$ & $2(0)$ & $12(2)$ & $3(0)$ & $26(3)$ & 12 \\
B & $4(1)$ & - & $5(2)$ & $5(1)$ & $14(4)$ & 29 \\
C & $12(3)$ & $1(0)$ & $7(1)$ & - & $20(4)$ & 20 \\
D & $10(1)$ & - & $13(2)$ & - & $23(3)$ & 13 \\
Total & $35(6)$ & $3(0)$ & $37(7)$ & $8(1)$ & $83(14)$ & \\
$\%$ & 17 & 0 & 19 & 13 & & 17 \\
\hline \hline
\end{tabular}

Table 4. Isolation of M. a. paratuberculosis from wild rabbit urine on four farms in the east of Scotland (numbers in parentheses indicate positive isolates)

\begin{tabular}{lrlllr}
\hline \hline Farm & $\begin{array}{l}\text { Adult } \\
\text { males }\end{array}$ & $\begin{array}{l}\text { Juvenile } \\
\text { males }\end{array}$ & $\begin{array}{l}\text { Adult } \\
\text { females }\end{array}$ & $\begin{array}{l}\text { Juvenile } \\
\text { females }\end{array}$ & $\begin{array}{r}\text { Total } \\
\text { tested }\end{array}$ \\
\hline A & $3(0)$ & - & $2(0)$ & - & $5(0)$ \\
B & $1(1)$ & - & - & $1(0)$ & $2(1)$ \\
C & $2(1)$ & - & - & - & $2(1)$ \\
D & $5(0)$ & - & $3(0)$ & - & $8(0)$ \\
Total & $11(2)$ & - & $5(0)$ & $1(0)$ & $17(2)$ \\
\hline \hline
\end{tabular}

determine the level of infection with paratuberculosis. Rabbits were sexed and classed as adults if weighing more than $1200 \mathrm{~g}$ [16]. Smears of lymph node, intestine and faeces were examined for acid-fast bacilli (AFB) by the Ziehl-Neelsen method [1]. Samples with AFB (i.e. $\mathrm{ZN}+$ ) were cultured and isolates of $\mathrm{Myco}$ bacterium spp. were identified by a polymerase chain reaction (PCR) to detect the IS900 insertion sequence for M. a. paratuberculosis [2].

To investigate the potential for urine to carry the organism, urine from the bladder of rabbits was collected aseptically using a vacutainer blood sampling tube. The urine was centrifuged at $2400 \mathrm{~g}$ for $30 \mathrm{~min}$ and the deposit cultured. Isolates of Mycobacterium spp. were identified by PCR and any mycobacterial isolated confirmed by IS900. Serial dilutions of faeces from infected rabbits were also cultured to determine the level of infection present.

\section{Relative input of bacteria onto grazing pasture}

The relative input of M. a. paratuberculosis from excreta of cattle sheep and wild rabbits was calculated for the four farms using stocking densities and known disease prevalence, combined with published excretion rates (for livestock) and data for rabbits calculated from this study (see Table 5 for equations).

\section{Statistical analysis}

Raw pellet and latrine data were multiplied (by 4 and 0.02 respectively) to obtain values per $\mathrm{m}^{2}$ and normalized by $\log (x+1)$ transformation [18]. Residual maximum likelihood (REML) [19] was used to estimate the mean values for fixed effects (farm, restricted access and position within field) and their interactions. Genstat REML option [20] was used which approximates standard errors of the differences for the field parameters. The REML model was used to determine the effects of different farms, restricted access and field position on: (1) numbers of rabbit faecal pellets $/ \mathrm{m}^{2}$; (2) numbers of latrines $/ \mathrm{m}^{2}$ and (3) sward heights $(\mathrm{mm})$. Wald tests from the REML routine were used to determine significant differences. The Wald statistic $(W)$ was quoted along with the relevant degrees of freedom and the probability value (compared to a $\chi^{2}$ distribution) for the fixed effects [20]. Log backtransformed means for faecal pellet and latrine density were presented with $95 \%$ confidence limits due to the restriction of backtransforming standard errors [21].

\section{RESULTS}

\section{Rates of pellet deposition}

The mean levels of rabbit faecal deposition, during the six 2-week periods monitored for the four farms, are presented in Table 1. There was considerable variation between farms with $\mathrm{D}$ having the least pellets deposited on grazing pasture. Farm D also had the lowest numbers of rabbits and consequently the least rabbit control conducted on any of the farms. Despite the recorded variation, the overall mean was relatively 
Table 5. The relative potential input of M. a. paratuberculosis onto grazing pasture based on excretion rates and prevalence for cattle, sheep and rabbits on four farms in the east of Scotland

\begin{tabular}{|c|c|c|c|c|c|c|c|}
\hline & $\begin{array}{l}\text { Stocking } \\
\text { density } \\
\text { (per ha) }\end{array}$ & $\begin{array}{l}\text { Defaecations } \\
\text { (per day) }\end{array}$ & $\begin{array}{l}\text { Weight of } \\
\text { defaecations }(\mathrm{g})\end{array}$ & $\begin{array}{l}\text { Weight of } \\
\text { defaecations } \\
\text { (g/ha per day) }\end{array}$ & $\begin{array}{l}\text { Prevalence of } \\
\text { paratuberculosis } \\
\text { (proportion) }\end{array}$ & $\begin{array}{l}\text { 'Infectivity' } \\
\text { of faeces } \\
\text { (c.f.u./g) }\end{array}$ & $\begin{array}{l}\text { Input onto pasture } \\
\text { (c.f.u./ha per day) }\end{array}$ \\
\hline Cattle & $0 \cdot 26^{\mathrm{a}}$ & $11 \cdot 15^{\mathrm{c}}$ & $1770 \cdot 00^{\mathrm{e}}$ & $5131^{\mathrm{h}}$ & $0 \cdot 040^{\mathrm{k}}$ & $1 \cdot 0 \times 10^{8 \mathrm{n}}$ & $2 \cdot 1 \times 10^{10 \mathrm{q}}$ \\
\hline Sheep & $1 \cdot 00^{\mathrm{b}}$ & $17 \cdot 33^{d}$ & $82 \cdot 50^{\mathrm{f}}$ & $1430^{\mathrm{i}}$ & $0 \cdot 004^{1}$ & $1.09 \times 10^{80}$ & $6 \cdot 2 \times 10^{8 \mathrm{r}}$ \\
\hline Rabbits & - & - & $0 \cdot 18^{\mathrm{g}}$ & $1234^{\mathrm{j}}$ & $0 \cdot 170^{\mathrm{m}}$ & $7 \cdot 6 \times 10^{5 p}$ & $1.7 \times 10^{8 \mathrm{~s}}$ \\
\hline
\end{tabular}

a,b mean for farms A, B, C and D; c, d,e, f means from [22]; ${ }^{\mathrm{g}}$ mean for 100 rabbit pellets from farms $\mathrm{A}, \mathrm{B}, \mathrm{C}$ and $\mathrm{D} ;{ }^{\mathrm{h}}(\mathrm{a} \times \mathrm{c} \times \mathrm{e})$; ${ }^{\mathrm{i}}(\mathrm{b} \times \mathrm{d} \times \mathrm{f}) ;{ }^{\mathrm{j}}(\mathrm{g} \times 7358 /$ ha from this study $) ;{ }^{\mathrm{k}, 1}$ mean for farms A, B, C and D for $1997 ;{ }^{\mathrm{m}, \mathrm{p}}$ from this study; ${ }^{\mathrm{n}}[8] ;{ }^{\circ}[9]$; $\mathrm{q}(\mathrm{h} \times \mathrm{k} \times \mathrm{n}) ;{ }^{\mathrm{r}}(\mathrm{i} \times 1 \times \mathrm{o}) ;{ }^{\mathrm{s}}(\mathrm{j} \times \mathrm{m} \times \mathrm{p})$.

constant over time (Table 1). For all of the farms over the study period the mean number of pellets $( \pm$ s.E. $)$ deposited per 2 weeks $/ \mathrm{m}^{2}$ was $10 \cdot 3 \pm 3 \cdot 6$, equivalent to $7357 \pm 2571$ pellets/ha per day.

\section{'Standing crop' of rabbit faeces}

The means for the numbers of pellets, latrines and sward heights for the four farms are presented in Table 2. There was no significant difference between farms $(W=5 \cdot 1$, D.F. $=3$, n.s. $)$ or field position - i.e. edge or middle $-(W=0 \cdot 2$, D.F. $=1$, n.s. $)$ with respect to the mean numbers of rabbit pellets present. Similarly for the number of latrines encountered there was no significant difference between farms $(W=1 \cdot 3$, D.F. $=3$, n.s. $)$ or field position $(W=0 \cdot 2$, D.F. $=1$, n.s. $)$. For sward height there was also no significant difference between farms $(W=4 \cdot 6$, D.F. $=3$, n.s. $)$ or field position ( $W=0 \cdot 2$, D.F. $=1, \mathrm{n} . \mathrm{s}$.). This suggests that for the four farms studied, differences between farms and within fields were not important with respect to the numbers of rabbit faecal pellets likely to be encountered or the height of the sward found.

Restricting rabbit access, however, had a significant effect on the mean numbers of pellets $(W=29 \cdot 3$, D.F. $=1, P<0 \cdot 01)$ and latrines $(W=9 \cdot 6$, D.F. $=1, P<$ $0 \cdot 01)$ present and the mean sward height $(W=17 \cdot 5$, D.F. $=1, P<0.01$ ), with pellet and latrine numbers lower and sward heights higher in fields with restricted rabbit access. There was a significant interaction between restricted access and farms for the number of pellets deposited $(W=24 \cdot 2, \quad$ D.F. $=2$, $P<0.01)$ and also for the number of latrines encountered $(W=7 \cdot 2$, D.F. $=2, P<0 \cdot 05)$. Fencing on one farm $(C)$ was more effective at reducing levels of rabbit faecal contamination than on the other farms.

Extrapolating means for fields without restricted access gave a minimum estimate of 61000 pellets/ha in the sward plus $>20000$ pellets in latrines (where a latrine has $>20$ pellets) or a total of $>81000$ pellets/ ha. For fields with restricted access the total was $>22000$ pellets/ha (i.e. 14000 pellets/ha $+>8000$ in latrines), approximately four times less than fields with no control.

\section{Prevalence of infection in rabbits and infectivity of excreta}

M. a. paratuberculosis was isolated from rabbits on all four farms with an overall prevalence of $17 \%$ (Table 3). Out of the subsample of 30 rabbits for which urine was available, M. a. paratuberculosis was isolated from two rabbits, one each from farms B and D (Table 4).

Serial dilutions to determine the number of colony forming units from infected faeces were completed for 7 samples (2 each from positive rabbits from farms A, B and C and 1 from farm D). The mean number of c.f.u./g from infected rabbit faeces was $7 \cdot 6 \times 10^{5} \pm 5 \cdot 2 \times 10^{5}$.

\section{Relative input of bacteria onto grazing pasture}

The relative input of M. a. paratuberculosis from excreta of cattle sheep and wild rabbits for the four farms are presented in Table 5. It was estimated that cattle, sheep and rabbits contribute $2 \cdot 1 \times 10^{10}, 6 \cdot 2 \times 10^{8}$ and $1 \cdot 6 \times 10^{8}$ c.f.u./ha respectively.

\section{DISCUSSION}

Until recently rabbits have been considered largely unimportant as sylvatic reservoirs of livestock diseases [23]. However, the recent detection of bovine viral diarrhoea (BVD) antibodies [24] and isolation $M$. a. paratuberculosis $[1,2]$ from wild rabbits suggests 
that they may play a role in the transmission of disease.

The aim of this study was to quantify the level of rabbit faecal contamination present on grazing pasture on farms where M. a. paratuberculosis had previously been isolated from livestock and rabbits. Significant quantities of rabbit faeces were encountered on all four farms studied. The mean deposition rate of 7357 pellets/ha was within the range predicted, based on reported rabbit densities for this part of Scotland and published faecal excretion rates [4-6]. However, this may be an underestimate since sheep continued to graze all fields during the study and may have ingested or trampled on pellets. Due to the accumulation of rabbit faeces over time, the mean 'standing crop' encountered was higher - especially for fields classed as having no restricted access (mean of $>61000$ pellets/ha).

Previous studies have shown evidence of $M$. $a$. paratuberculosis infection in $8-100 \%$ of rabbits tested on farms infected with paratuberculosis in the east of Scotland [1,2]. The figures of 13 and $29 \%$ reported here are at the lower end of this range. This may in part be due to the inclusion of juvenile rabbits, which had a much lower prevalence of infection $(9 \%$ as opposed to $18 \%$ for adults in the sample tested here although only a small sample size), but may also be due to the fact that only tissue and faeces from smear positive rabbits were cultured. The isolation of $M . a$. paratuberculosis from rabbit faeces indicates that rabbits on these four farms were infected with paratuberculosis as has been previously demonstrated [1].

This is the first reported isolation of M. a. paratuberculosis from urine in wild rabbits. Urine, therefore, may represent another potential mode of transmission onto grazing pasture. For example, badger Meles meles urine is regarded as a potential source of transmission of M. bovis [25]. However, to date urine has not been implicated in the epidemiology of paratuberculosis partly because urine is known to have an inhibitory effect on the growth of the bacteria in culture media [26]. Furthermore we did not determine the infectivity of rabbit urine in this study and therefore have no data on the potential risk that it may represent. On the other hand $M$. a. paratuberculosis does not grow out with its host and therefore the inhibitory effect may not be relevant. Also, during grazing, swards contaminated by urine may not be avoided to the same extent as faeces [25]. The importance of rabbit urine in the epidemiology of paratuberculosis should be further investigated.

\section{The disease risk to livestock and the efficacy of rabbit control measures}

Fields to which rabbit access was restricted had significantly lower numbers of rabbit pellets present even when the effects of the low numbers of rabbits on farm $\mathrm{D}$ (where no restriction was practiced) were taken into account. Furthermore, the higher sward heights associated with restricted rabbit access may further reduce the risk of livestock ingesting pellets. It has been demonstrated that the risks of $M$. bovis transmission to cattle grazing pasture contaminated with badger excreta, are increased as sward height is decreased [25].

Although, the calculations presented in Table 5 directly equate prevalence of infection with excretion rate, this is unlikely as animals excrete at different rates depending on the stage of their infection [10]. Nevertheless from these crude calculations it is apparent that at the livestock density and disease prevalence on the four farms studied here, sheep and cattle contribute approximately 4 and 125 times more organisms/ha per day respectively than rabbits. However, rabbits could potentially contribute 170 million c.f.u./ha per day of M. a. paratuberculosis (Table 5) plus additional bacteria through urine. Given that one infected pellet carries a mean of $1 \cdot 3 \times 10^{5}$ c.f.u., then the ingestion of a small number of infected rabbit pellets could constitute an infective dose. Consequently contamination by rabbit excreta on infected farms may represent a significant disease risk to livestock.

\section{ACKNOWLEDGEMENTS}

We thank the landowners of the four farms for their cooperation in providing access to land, box traps and information concerning livestock. Amanda Pirie and Karen Rudge assisted with PCR and IS900 analyses of samples. Dave Allcroft provided statistical advice. Pip Beard and Ilias Kyriazakis provided helpful comments on the manuscript. This work was supported by a grant from the Scottish Executive for Rural Affairs Department.

\section{REFERENCES}

1. Greig A, Stevenson K, Perez V, Pirie AA, Grant JM, Sharp JM. Paratuberculosis in wild rabbits (Oryctolagus cuniculus). Vet Rec 1997; 140: 141-3.

2. Greig A, Stevenson K, Henderson D, et al. Epidemiological study of paratuberculosis in wild rabbits in Scotland. J Clin Microbiol 1999; 37: 1746-51. 
3. Clarke CJ. The pathology and pathogenesis of paratuberculosis in ruminants and other species. J Comp Pathol 1997; 116: 217-61.

4. Kolb HH. The use of cover and burrows by a population of rabbits (Mammalia: Oryctolagus cuniculus) in eastern Scotland. J Zool Lond 1994; 223 : 9-17.

5. Lockley RM. Production of faecal pellets in the wild rabbit. Nature 1962; 194: 988-9.

6. Wood DH. Estimating rabbit density by counting dung pellets. Aus Wildl Res 1988; 15: 665-71.

7. Sneddon IA. Latrine use by the European rabbit (Oryctolagus cuniculus). J Mammal 1991; 72: 769-75.

8. Cranwell MP. Johne's disease: past and present. Cattle Prac 1997; 5: 217-23.

9. Whittington RJ, Reddacliff LA, Marsh I, McAllister S, Saunders V. Temporal patterns and quantification of excretion of Mycobacterium avium subsp paratuberculosis in sheep with Johne's disease. Aus Vet J 2000; 78: 34-7.

10. Sweeney RW. Transmission of paratuberculosis. Vet Clin Nor Am Food Anim Prac 1996; 12: 305-12.

11. Stehman SM. Paratuberculosis in small ruminants, deer and South American camelids. Vet Clin Nor Am Food Anim Prac 1996; 12: 441-56.

12. Jorgensen JB. Survival of Mycobacterium paratuberculosis in slurry. Nord Vet Med 1977; 29: 267-70.

13. Boag B. Reduction in numbers of wild rabbit (Oryctolagus cuniculus) due to changes in agricultural practices and land use. Crop Protect $1987 ; 6$ : 347-51.

14. Bell AC, Byrne PM, Watson S. The effect of rabbit (Oryctolagus cuniculus) grazing damage on the growth, botanical composition and yield of a ryegrass re-seed. Ann Appl Biol 1999; 135: 417-24.

15. Thompson HV. The rabbit in Britain. In: Thompson HV, King CM, eds. The European rabbit. The history and biology of a successful colonizer. Oxford: Oxford University Press, 1994: 64-107.

16. Cowan DP. The rabbit. In: Corbet GB, Harris S, eds. A handbook of british mammals. Oxford: Blackwell Scientific, 1991: 146-54.

17. Barthram GT. Experimental techniques: the HFRO sward stick. In: Biennial Report 1984-1985. Penicuick: Hill Farming Research Organisation, 1985: 29-30.

18. Fowler J, Cohen L. Practical statistics for field biology. Buckingham: Open University Press, 1990.

19. Patterson HD, Thompson R. Recovery of inter-block information when block sizes are unequal. Biometrica $1971 ;$ 58: 545-54.

20. Lawes Agricultural Trust. Genstat 5 reference manual. Oxford: Claredon Press, 1993.

21. Zar JH. Biostatistical analysis. New Jersey: PrenticeHall International, 1984.

22. Haynes RJ, Williams PH. Nutrient cycling and soil fertility in the grazed pasture ecosystem. Advan Agron 1993; 49: 119-97.

23. Saulai M, Cabaret J. Limited role of lagomorphs (Oryctolagus cuniculus and Lepus capensis) in the dispersion of parasite nematodes of ruminants. Vet Parasitol 1998; 77 : 301-4.

24. Frolich K, Streich WJ. Serologic evidence of bovine viral diarrhea virus in free-ranging rabbits from Germany. J Wild Dis 1998; 34: 173-8.

25. Hutchings MR, Harris S. Quantifying the risks of TB infection to cattle posed by badger excreta. Epidemiol Infect 1999; 122: 167-74.

26. Whitlock RH, Rosenberger AE, Siebert M, Sweeney RW. Environmental contamination on dairy farms with cattle infected with Mycobacterium paratuberculosis. Proc World Butr Congr 1992; 1: 84-8. 